\title{
Producción de anticuerpos policlonales IgG contra la proteína iduronato-2-sulfato sulfatasa y desarrollo de un sistema de detección para IDS humana recombinante
}

\author{
Olga Peña *, Ángela Sosa *, Olga Echeverri, Homero Sáenz, Luis A. Barrera \\ Instituto de Errores Innatos del Metabolismo (IEIM), Pontificia Universidad Javeriana, \\ Bogotá, D. C., Colombia. \\ * Los dos autores contribuyeron igualmente para este trabajo.
}

Introducción. La enfermedad de Hunter es un trastorno lisosómico caracterizado por la deficiencia de la enzima iduronato-2-sulfato sulfatasa (IDS) (EC 3.1.6.13). Esta enfermedad, al igual que muchos trastornos metabólicos, son patologías intratables mediante la terapéutica convencional; sin embargo, existe la posibilidad de ser tratada alternativamente mediante terapia génica o terapia de reemplazo enzimático.

Objetivo. El Instituto de Errores Innatos del Metabolismo (IEIM) ha desarrollado un sistema de expresión de sulfatasas para producir IDS humana recombinante (IDShr) en Escherichia coli y Pichia pastoris, con resultados favorables. El objetivo principal de este trabajo fue desarrollar un sistema de detección de IDS humana recombinante.

Materiales y métodos. Para el efecto, se inmunizaron con IDS comercial de TKT (Cambridge, MA) dos conejos de raza Nueva Zelanda blanca y los anticuerpos purificados a partir del suero se utilizaron en el desarrollo de una técnica semicuantitativa por dot-blot. Diferentes muestras de extractos crudos de fermentaciones con $P$. pastoris y $E$. coli se procesaron con el fin de poder determinar la presencia de la enzima.

Resultados. Se demostró que los anticuerpos eran específicos en el reconocimiento de la IDS sin presentar reactividad cruzada con proteínas contaminantes de los extractos crudos. Conclusión. Por consiguiente, los anticuerpos se podrán usar en el desarrollo de una técnica ELISA tipo sandwich como método de detección y cuantificación de la enzima y en procesos de purificación de la misma mediante cromatografía de afinidad.

Palabras clave: mucopolisacaridosis I, iduronato sulfatasa, síndrome de Hunter, terapia de reemplazo enzimático, anticuerpos policlonales, dot-blot, anticuerpos policlonales.

Production of polyclonal antibodies to protein iduronate-2-sulphate sulphatase (IDS) and development of a detection system for human recombinant IDS

Introduction. Hunter syndrome is a lysosomal disorder characterized by iduronate 2-sulphate sulphatase (IDS) genetic deficiency. Although MPS type II (Hunter) has no cure, enzyme replacement therapy (ERT) and gene therapy are potential new approaches to treatment.

Objective. The Institute for the Study of Innate Errors of Metabolism is currently developing a sulphatase expression system through human recombinant IDS (hrIDS) in Pichia pastoris and Escherichia coli.

Material and methods. A monitoring method for IDS was developed by production of polyclonal antibodies from rabbit against human IDS. Two New Zealand white rabbits were immunized with commercial IDS. These antibodies were used in a dot-blot method for detection and partial quantification of human recombinant IDS. P. pastoris and E. coli fermentation crude extracts were processed to determine IDS presence.

Results. The antibodies were demonstrably IDS specific, without cross reaction with crude extract contaminant proteins.

Conclusion. Therefore, these antibodies can be used to establish an ELISA sandwich system as a method for detecting and quantifying a protein of interest. The antibodies can also be employed in an affinity chromatography step during the IDS purification process.

Key words: mucopolysaccharidosis, IDS, Hunter syndrome, ERT, polyclonal antibodies 
Los errores innatos del metabolismo son un grupo de enfermedades genéticas poco frecuentes, dentro de las cuales se encuentran los trastornos lisosómicos como las mucopolisacaridosis.

La mucopolisacaridosis tipo II o síndrome de Hunter (OMIM: 309900) se clasifica como una enfermedad de herencia ligada al cromosoma $X$ $(1,2)$. Es causada por deficiencia de la iduronato 2-sulfato sulfatasa (IDS), codificada por el gen IDS, ubicado en la región Xq27.3-Xq28. Este gen contiene $24 \mathrm{~kb}$, aproximadamente, y está compuesto por 9 exones y 8 intrones $(3,4)$.

Esta enzima cataliza la remoción del sulfato en la posición C2 del ácido L-idurónico presente en el heparán sulfato y dermatán sulfato (1); la deficiencia de esta reacción no permite la degradación completa de dichos sustratos y explica su acumulación y excreción.

El diagnóstico de la enfermedad en el laboratorio se realiza mediante la determinación de mucopolisacáridos en orina y deficiencia enzimática en células como leucocitos y fibroblastos (5).

Las alteraciones o mutaciones que ocurren en el gen de la IDS se traducen en anomalías estructurales y de actividad, lo cual origina con ello la deficiencia enzimática y el acúmulo de mucopolisacáridos en diferentes tejidos. Esto produce manifestaciones clínicas de la enfermedad como facies toscas, hepatoesplenomegalia, trastornos respiratorios y cardiovasculares, retardo mental y del desarrollo.

La incidencia que se ha reportado de esta enfermedad en Israel entre 1967 y 1975 fue de 1:34.000 nacidos (6); en el Reino Unido se estimó en 1:132.000 (7), y en British Columbia en 1:111.000 (8). En Colombia aún no existen datos de prevalencia o incidencia para esta enfermedad.

Para el tratamiento de la enfermedad de Hunter se ha intentado el trasplante de médula ósea y el

Correspondencia:

Luis Alejandro Barrera, Instituto de Errores Innatos del Metabolismo, Pontificia Universidad Javeriana, Bogotá, D.C. Colombia.

Teléfono: 320 8320, ext. 4125-4089; fax: 3384548

abarrera@javeriana.edu.co

Recibido: 02/09/04; aceptado: 28/02/05 intercambio de plasma (9-11) sin obtener resultados favorables. Recientemente, se han intentado otras medidas terapéuticas como la terapia génica (12) y la terapia de reemplazo enzimático (13). In vitro se ha logrado corregir la deficiencia enzimática en fibroblastos Hunter, empleando IDS expresada en células Chinese Hamster Ovari (CHO) (14); sin embargo, existen limitantes para el uso de la terapia de reemplazo enzimático, como los altos costos de producción de la enzima y la necesidad de dosis frecuentes.

La utilización de tecnologías de ADN recombinante para expresar proteínas foráneas permite obtener grandes cantidades de proteína, superiores a las extraídas de fuentes naturales. $(15,16)$. Por tal razón, el Instituto de Errores Innatos del Metabolismo está tratando de producir de forma heteróloga la IDS humana recombinante (IDShr) en Escherichia coli y Pichia pastoris, con miras a obtener la enzima pura para implementar un tratamiento de reemplazo enzimático en la enfermedad de Hunter.

Para el desarrollo de los procesos de producción y purificación de la enzima, en este trabajo se obtuvo un anticuerpo policlonal anti-IDS que se utilizó en un sistema de detección de IDS por dotblot para el control de la producción enzimática y en la construcción de una columna de afinidad que se está usando en el proceso de purificación de la proteína.

\section{Materiales y métodos}

\section{Producción de un suero policlonal anti-IDS}

Para la producción de anticuerpos anti-IDS se utilizó IDS I2S0201G recombinante, altamente purificada producida en células $\mathrm{CHO}$, la cual fue donada por la empresa Transkariotic Therapies. Su concentración proteica, actividad enzimática y peso molecular fue confirmada mediante técnicas convencionales de Folin-Lowry (17) en un espectrofotómetro Biospec-1601 (Shimadzu Corporation) a $620 \mathrm{~nm}$, fluorometría (18) y SDSpage (19), respectivamente.

El esquema de inmunización se llevó a cabo en el Bioterio de la Facultad de Medicina Veterinaria y Zootecnia de la Universidad Nacional de Colombia. Se utilizaron dos conejos de raza Nueva Zelanda blanca con una edad 10 semanas. Los 
conejos se inmunizaron cuatro veces por vía intradérmica a intervalos de 7 días, con dos concentraciones diferentes de IDS $(100 \mu \mathrm{g} / \mathrm{ml}$ y $50 \mathrm{mg} / \mathrm{ml}$ ), utilizando como vehículo adyuvante completo e incompleto de Freund (20).

El manejo de los animales fue aprobado por el Comité de Bioética de la Facultad de Ciencias de la Pontificia Universidad Javeriana y cumplió con las normas establecidas para el efecto según lo dispuesto en la Resolución No. 008430 del Ministerio de Salud.

\section{Purificación de anticuerpos policlonales anti-IDS}

Se realizó a partir del suero de los conejos, mediante la utilización de una columna de afinidad Hi Trap Protein A (Amersham Pharmacia Biotech () ); para la separación se utilizó una bomba peristáltica con flujo constante del suero, a una velocidad aproximada de $1 \mathrm{ml} / \mathrm{min}$. El proceso de elución se realizó en solución tampón de ácido cítrico $0,1 \mathrm{M}, \mathrm{pH} 3,6$; las fracciones recolectadas se cuantificaron por el método de Folin-Lowry en un espectrofotómetro Biospec1601 (Shimazu Corporation) a $620 \mathrm{~nm}$, y se evaluaron por SDS-page.

\section{Titulación de los anticuerpos policlonales anti-IDS}

El título de los anticuerpos se determinó por el método de dot-blot en una cámara Bio-Dot ${ }^{\mathrm{TM}}$ Aparatus de Biorad. El antígeno se adicionó en una concentración constante de $25 \mu \mathrm{g} / \mathrm{ml}$ a una membrana de nitrocelulosa Hybond de 0,22 nm; como control negativo de la prueba se adicionó TBS (Tris Base 20 mM, NaCl 500 mM, pH 7,5). La membrana fue bloqueada con una solución de TTBS (TBS-Tween 20 al 0,1\%) BSA 2\%.

Posteriormente, se realizaron diluciones seriadas dobles de las fracciones obtenidas durante el proceso de purificación en TTBS-BSA al $2 \%$. Se utilizaron como controles sueros preinmunes de cada uno de los conejos. Por último, se adicionó el conjugado anti-lgG de conejo, conjugado a peroxidasa (Sigma A-9169) a una concentración de $0,4 \mu \mathrm{g} / \mathrm{ml}$ en solución TTBS-BSA al $2 \%$. La prueba se visualizó con solución cromogénica de 3'-3' diaminobenzidina durante 30 segundos.

\section{Determinación de la especificidad de anticuerpos policlonales anti-IDS}

La especificidad de los anticuerpos se determinó mediante la técnica de Western blot. Las proteínas presentes en los extractos crudos de $P$. pastoris y la IDS pura se separaron mediante SDS-page y se transfirieron a papel de nitrocelulosa Hybond; la membrana se cortó en tiras y se bloqueó en solución de TTBS y leche descremada al 5\%. Como anticuerpo primario se utilizó lgG de conejo anti-IDS y como control positivo, un anticuerpo monoclonal anti-IDS donado por Kasuko Sukegawa de la Universidad de Gifu de Japón. Los anticuerpos secundarios que se usaron fueron anti-IgG de conejo marcado con peroxidasa (Sigma A-9169) y anti-IgG de ratón, conjugado a peroxidasa (Sigma A-9044), respectivamente.

\section{Desarrollo de una técnica semicuantitativa para IDS por dot-blot}

Se desarrollo una primera fase utilizando el anticuerpo policlonal anti-IDS en cuatro diluciones diferentes $(1 / 500,1 / 1.000,1 / 2.000$ y $1 / 4.000)$ enfrentado a varias concentraciones de IDS pura en diluciones seriadas por duplicado desde $60 \mu \mathrm{g}$ hasta $1 \mathrm{ng} / \mathrm{ml}$.

Posteriormente, se realizó una curva de calibración utilizando diluciones seriadas por duplicado desde $10 \mu \mathrm{g} / \mathrm{ml}$ hasta $0,3 \mu \mathrm{g} / \mathrm{ml}$. Los extractos crudos de $P$. pastoris y E.coli se procesaron con anticuerpo primario IgG anti-IDS en dilución 1/ 2.000 .

\section{Resultados}

\section{Características de la IDS I2S0201G}

Usando el método de Folin-Lowry se obtuvo una concentración proteica de $1,7 \mathrm{mg} / \mathrm{ml}$. Los resultados de la actividad enzimática fueron de alrededor de 1,2 $\mathrm{mU} / \mathrm{mg}$, lo que se ajusta al rango dado por TKT (1,0-3,5 mU/mg). Mediante SDSpage se pudo evidenciar que el peso molecular de la IDS I2S0201G se encuentra entre 70 y 90 $\mathrm{kd}$, al igual que su alto grado de pureza (figura 1).

\section{Purificación y titulación de anticuerpos}

La purificación de los anticuerpos se realizó a partir del suero obtenido del sangrado total de cada uno de los conejos, y se obtuvieron cuatro 


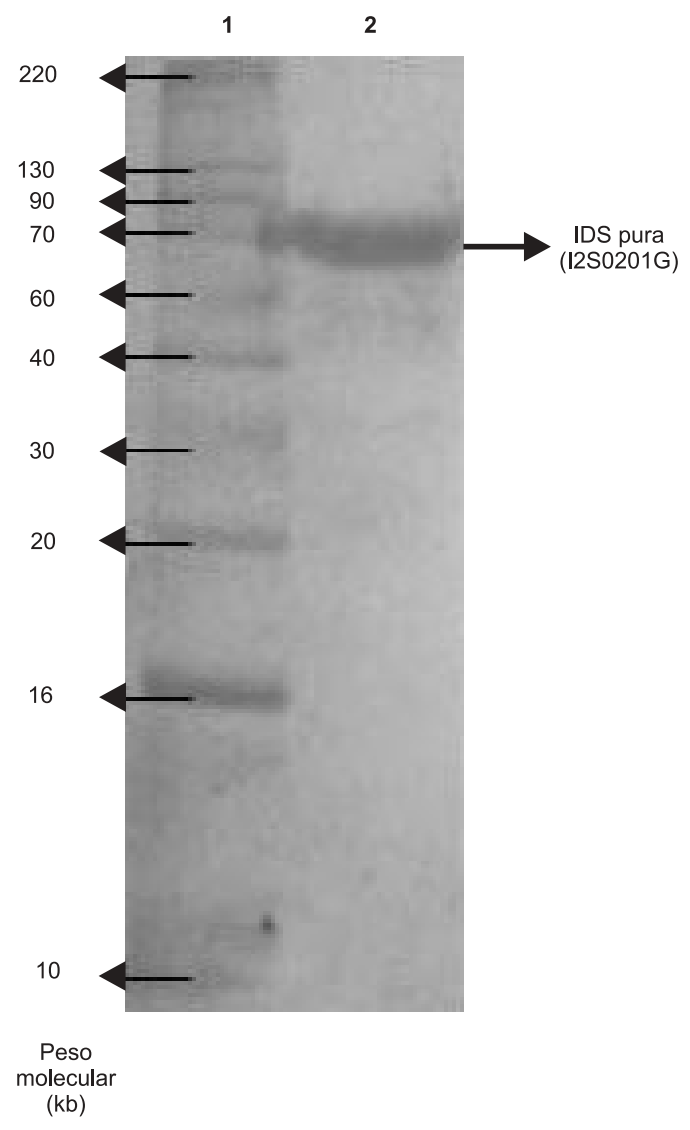

Figura 1. Electroforesis de IDS I2S0201G. Carril 1: marcador de peso molecular en kd; carril 2: IDS I2S0201G. En el corrido se muestra una sola banda correspondiente a la IDS con un peso molecular aproximado entre 80 y $90 \mathrm{kd}$. fracciones del proceso de elución (figura 2), en las que se observó una mayor concentración de proteínas en las fracciones 1 y 2 (cuadro 1). Los resultados de título obtenidos para el conejo 1 fueron de $1 / 65.536,1 / 32.768,1 / 16.384$ y $1 / 2.048$ para las fracciones 1, 2, 3 y 4, respectivamente. En el conejo 2, los títulos obtenidos fueron de $1 /$ $16.384,1 / 2.048,1 / 256$ y $1 / 128$ para las fracciones en el mismo orden (figura 3 , cuadro 1 ).

\section{Determinacion de especificidad de anticuerpo policlonal anti-IDS}

En la prueba de Western blot se pudo evidenciar el reconocimiento de una sola banda por parte del anticuerpo policlonal anti-IDS a partir del extracto crudo de $P$. pastoris, la cual se encuentra a la misma altura de la banda de IDS I2S0201G reconocida por este mismo anticuerpo y por el anticuerpo monoclonal (figura 4).

\section{Implementación de una técnica semicuantitativa para IDS por dot-blot}

Los títulos de anticuerpos obtenidos fueron muy similares. Las diluciones del anticuerpo $1 / 500$, $1 / 1.000,1 / 2.000$ y $1 / 4.000$ presentaron reconocimiento de la proteína en concentraciones mínimas de $0,07 \mu \mathrm{g} / \mathrm{ml}, 0,15 \mu \mathrm{g} / \mathrm{ml}, 0,3 \mu \mathrm{g} / \mathrm{ml}$ y $0,6 \mu \mathrm{g} / \mathrm{ml}$, respectivamente (figura 5)

Se evidenció que la dilución óptima del anticuerpo fue de $1 / 2.000$, con buen reconocimiento del antígeno a diversas concentraciones. Las
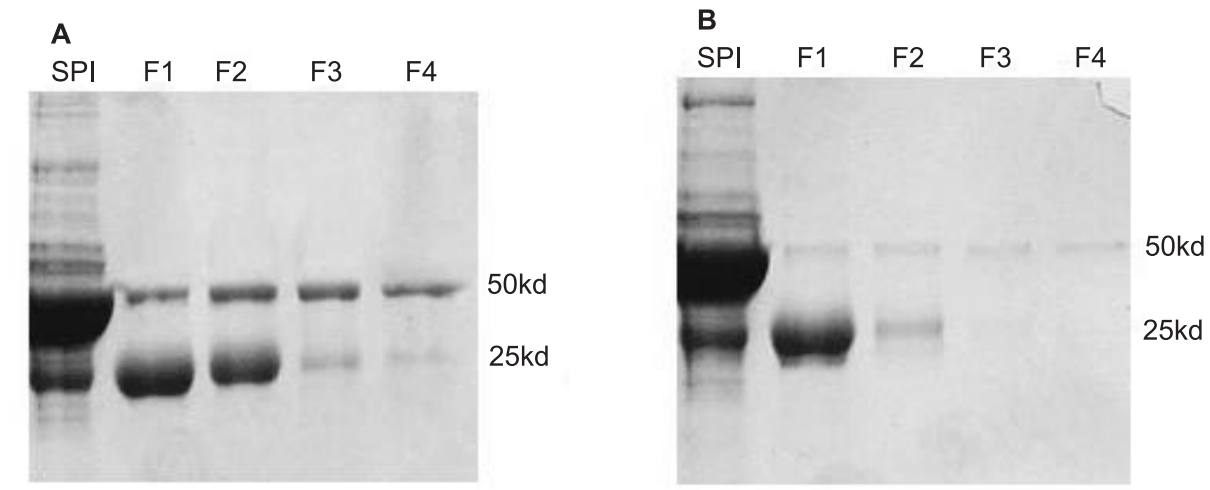

Figura 2. Electroforesis de las cuatro fracciones purificadas del suero obtenido del conejo 1 (A) y conejo 2 (B), que muestran las cadenas pesadas y livianas de los anticuerpos purificados, con pesos de $50 \mathrm{~kb}$ y $25 \mathrm{~kb}$, respectivamente. SPI: suero preinmune 
Cuadro 1. Concentración de proteínas y título obtenido de cada una de las muestras recolectadas antes y después del proceso de purificación mediante el uso de columna de afinidad Hi-Trap.

\begin{tabular}{lccccc}
\hline & \multicolumn{2}{c}{ Conejo 1 } & & \multicolumn{2}{c}{ Conejo 2 } \\
\cline { 2 - 3 } \cline { 5 - 6 } & [Proteínas $\mathbf{~ m g / m l ] ~}$ & Título por dot-blot & & [Proteínas $\mathbf{~ m g / m l ] ~}$ & Título por dot-blot \\
\hline Suero puro & 39,6 & & & 43,6 & $1 / 16.384$ \\
Fracción 1 & 13,1 & $1 / 65.536$ & & 7,84 & $1 / 2.048$ \\
Fracción 2 & 7,5 & $1 / 32.768$ & & 2,1 & $1 / 256$ \\
Fracción 3 & 2,0 & $1 / 16.384$ & & 0,1 & $1 / 128$ \\
Fracción 4 & 0,01 & $1 / 2.048$ & & 0,01 & \\
\hline
\end{tabular}
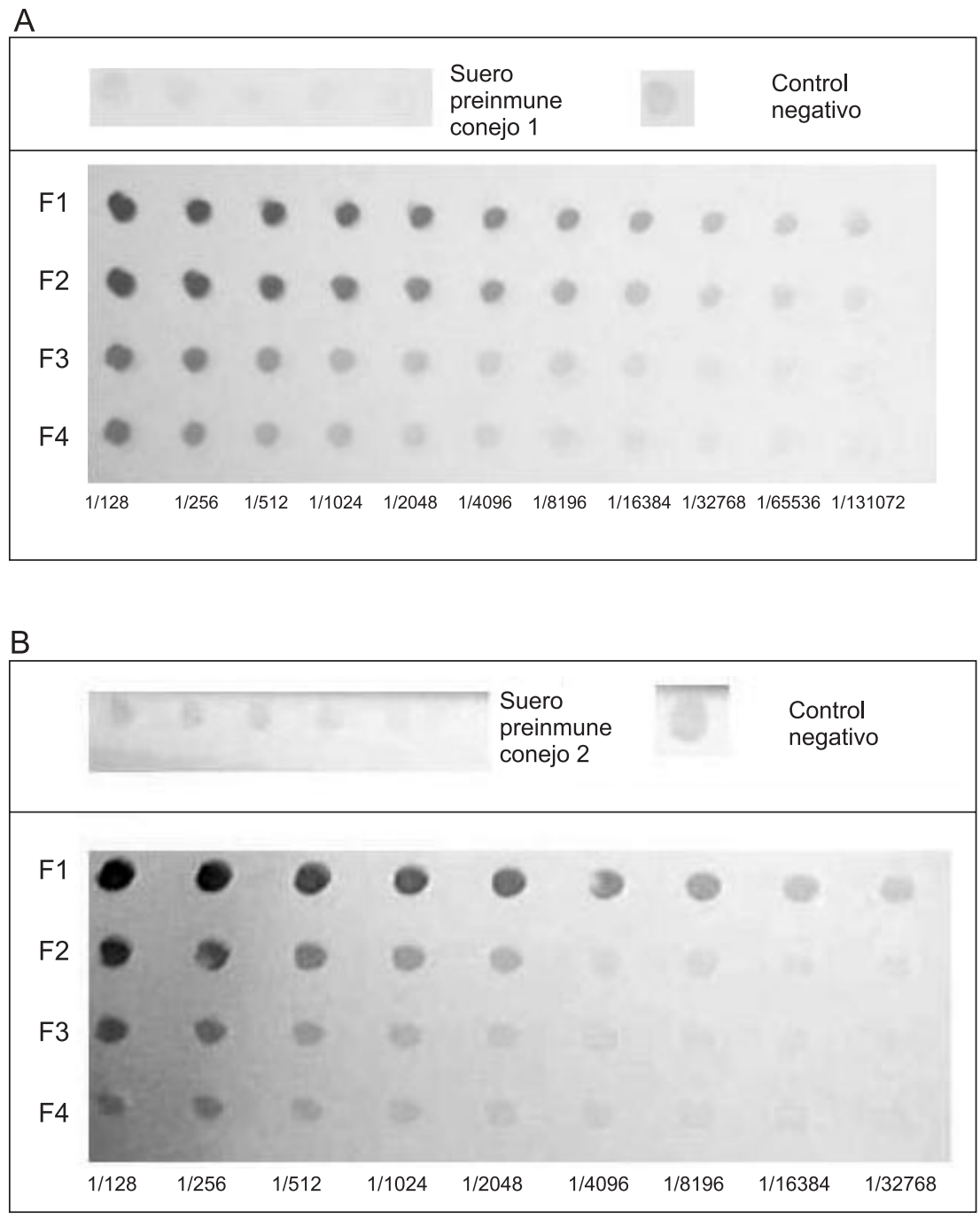

Figura 3. Titulación de anticuerpos (1/128-1/131.072) obtenidos de las cuatro fracciones (F1, F2, F3 y F4) obtenidas del proceso de purificación de los sueros de los conejos 1 (A) y 2 (B). Para el control negativo de la prueba se omitió la adición de antígeno a la membrana; de igual manera, se realizaron controles utilizando suero preinmune de los dos conejos. 


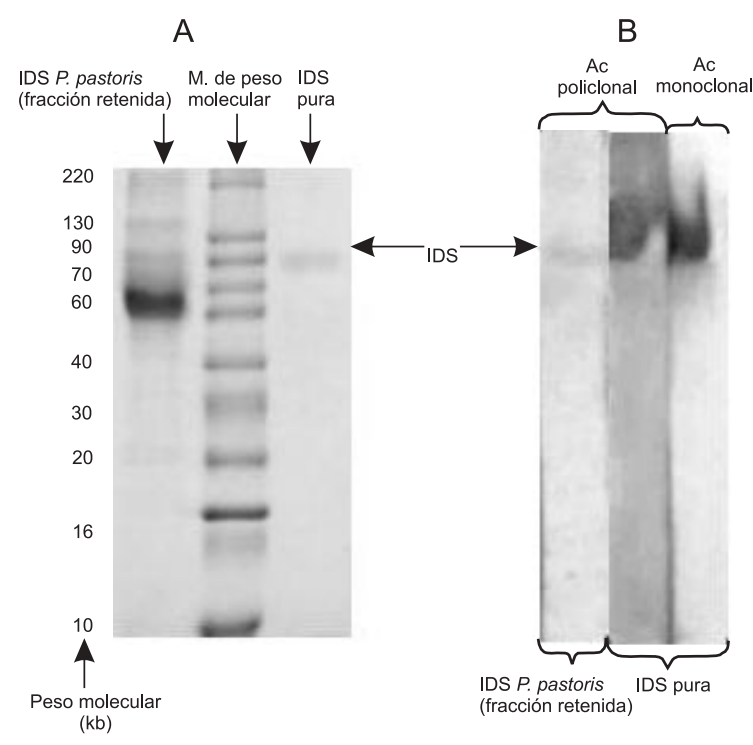

Figura 4. Reconocimiento específico de IDShr producida por $P$. pastoris. (A). Electroforesis de la fracción retenida de ultrafiltración de sobrenadante de $P$. pastoris en la que se muestran diferentes bandas de distinto peso molecular para ilustrar, también, el corrido electroforético de la IDS pura. Sin embargo, cuando se realiza el Western Blot (B) en esta misma fracción, el anticuerpo policlonal es capaz de reconocer una sola banda que se encuentra a la misma altura de la IDS pura reconocida por el anticuerpo monoclonal. diferentes tonalidades observadas permitieron desarrollar una curva de calibración que sirvió para deducir más fácilmente la concentración aproximada de IDS encontrada en los extractos crudos.

Para la curva de calibración se usó $10 \mu \mathrm{g} / \mathrm{ml}$ como valor máximo, pues concentraciones superiores a este valor presentaron superposición de tonalidades. El rango discriminatorio de nuestro método está, por lo tanto, entre $0,3 \mu \mathrm{g} / \mathrm{ml}$ y $10 \mu \mathrm{g} /$ $\mathrm{ml}$. Los valores superiores o inferiores no son confiables (figura 6).

\section{Discusión}

Las propiedades de la IDS I2S0201G utilizada como antígeno: peso molecular, actividad enzimática, concentración proteica y pureza, fueron similares a las suministradas por TKT. EI protocolo de inmunización en conejos mostró que al usar una concentración de antígeno de $100 \mu \mathrm{g} /$ $\mathrm{ml}$, se obtenía un mayor título que con la concentración de $50 \mu \mathrm{g} / \mathrm{ml}$, y en el proceso de purificación se observó que las mayores concentraciones de proteína se encontraban en las dos primeras fracciones eluídas, resultado que coincide con el título obtenido en dichas muestras.

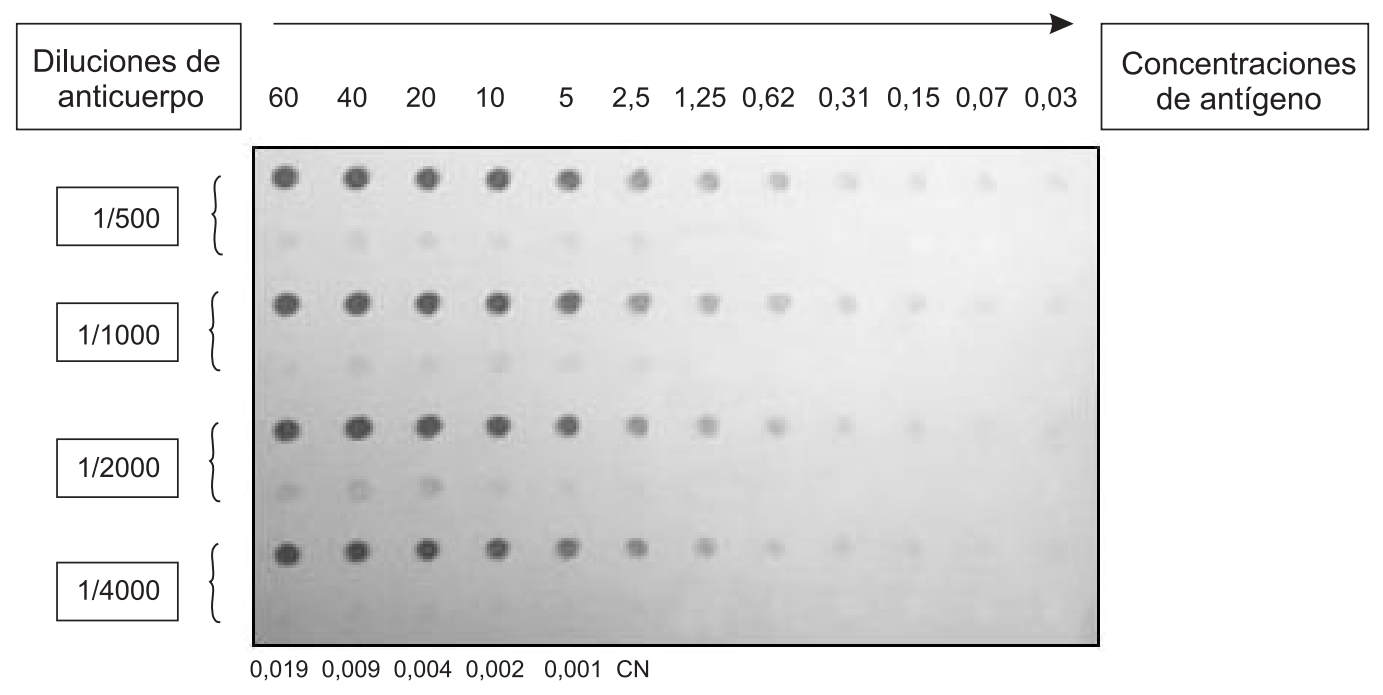

Figura 5. Fase de estandarización de la técnica de dot-blot como método semicuantitativo de IDS, a diferentes concentraciones del anticuerpo enfrentado a diferentes concentraciones del antígeno $(\mu \mathrm{g} / \mathrm{ml})$. 


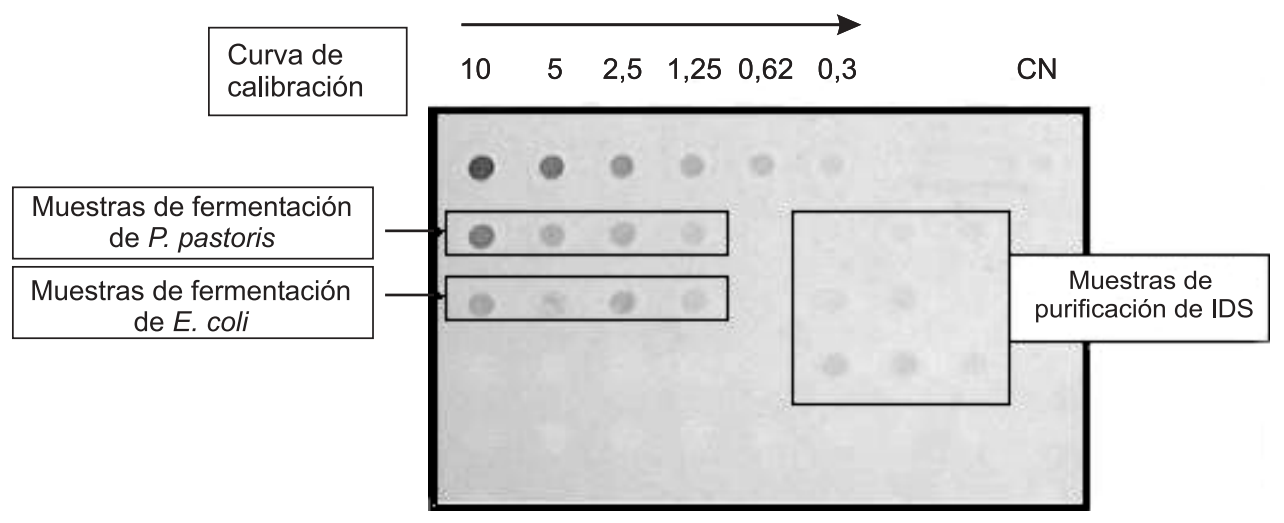

Figura 6. Prueba de dot-blot como método semicuantitavo para IDShr. Muestra los resultados del ensayo, en el cual se puede analizar la curva de calibración (IDS $\mu \mathrm{g} / \mathrm{ml}$ ) frente a cada una de las muestras problema (fermentaciones de $P$. pastoris y E. coli).

El alto grado de pureza de la proteína IDS utilizada en el esquema de inmunización permitió que los anticuerpos obtenidos no presentaran reactividad cruzada contra las proteínas presentes en los extractos crudos de $P$. pastoris, lo cual se pudo evidenciar mediante la técnica de Western blot, pues sólo una banda es reconocida por el anticuerpo, que se encuentra a la misma altura de la banda de IDS I2S0201G reconocida por el anticuerpo monoclonal donado por Sukegawa. Esto sugiere que el anticuerpo producido se puede usar en procesos de detección y purificación de la proteína, pues no existe reactividad cruzada contra proteínas contaminantes de $P$. pastoris, disminuyendo la posibilidad de obtener resultados falsos positivos en el proceso de control.

Se desarrolló la prueba de dot-blot como método semicuantitativo para la detección de IDShr, determinando que la dilución óptima de anticuerpo era $1 / 2.000$ y que para la curva de calibración se usarán concentraciones de IDS I2S0201G entre $10 \mu \mathrm{g} / \mathrm{ml}$ y $0,3 \mu \mathrm{g} / \mathrm{ml}$. Esta curva servirá como patrón para determinar concentraciones aproximadas de IDShr presente en los extractos crudos de $P$. pastoris y E. coli y en los diferentes pasos de purificación de la misma.

El anticuerpo producido se está utilizando en columnas de afinidad para mejorar el proceso de purificación de la enzima humana recombinante que estamos produciendo en $P$. pastoris y para supervisar los diferentes pasos de purificación de la enzima (21).

La producción de anticuerpos policlonales contra IDS fue publicado por el grupo de J. Hopwood en 2004 (22) y, recientemente, se ha producido un anticuerpo monoclonal que está próximo a publicarse (23). Estos anticuerpos no se hallan disponibles en las cantidades requeridas para los procesos de purificación y caracterización de una nueva enzima. Esto hizo necesaria la obtención de un anticuerpo policlonal útil en el proceso de purificación de la enzima y en la implementación de un sistema propio para la detección y cuantificación de la proteína durante los procesos de producción en P. pastoris.

\section{Agradecimientos}

El presente trabajo fue posible gracias a la donación de la enzima IDS I2S0201G por la empresa TKT, del anticuerpo monoclonal anti-IDS por la doctora Sukegawa de la Universidad de Gifu, y a la colaboración del Laboratorio de Inmunobiología de la Facultad de Ciencias de la Pontificia Universidad Javeriana.

\section{Conflicto de intereses}

La enzima IDS utilizada en el presente trabajo fue donada por la empresa TKT (Cambridge, MA), con la condición de que en caso de ser usada para fines comerciales el Instituto de Errores Innatos del Metabolismo deberá informar a TKT 
para negociar la forma de participación de cada una de las partes. El anticuerpo acá producido sólo será usado con fines de investigación.

\section{Financiación}

El presente trabajo fue posible gracias al apoyo financiero de la Pontificia Universidad Javeriana bajo el proyecto con código presupuestal 12060080102103 y al convenio con Colciencias No. 031-2002 para la formación de un joven investigador en el IEIM.

\section{Referencias}

1. Neufeld E, Muenzer J. The mucopolysaccharidoses. En: Scriver CR, Beaudet A, Sly W, Valle D, editors. The metabolic and molecular bases of inherited disease. $8^{\text {th }}$ edition. New York: Mc Graw-Hill Inc.; 2001. p.3421-41.

2. Petruschka L, Zschaiesche M, Bielicki J, Seidlitz G, Machill G, Hopwood JJ et al. Mucopoly-saccharidosis type II (Hunter syndrome): characterization of the iduronate-2-sulphatase in MPS II skin fibroblasts. J Inherit Metab Dis 1994;17:89-92.

3. Wilson PJ, Meaney CA, Hopwoop JJ, Morris CD. Sequence of the human iduronate 2-sulphatase (IDS) gene. Genomics 1993;17:773-5.

4. Flomen RH, Green ED, Green PM, Bentley DR, Giannelli F. Determination of the organization of coding sequences within the iduronate sulphate sulphatase (IDS) gene. Hum Mol Genet 1993;2:5-10.

5. Barrera L, Sáenz H, Cuéllar Y, Ospina S, Garzón K, Cabrera $\mathbf{M}$ et al. Manual de enfermedades metabólicas. Bogotá: Instituto de Errores Innatos del Metabolismo Pontificia Universidad Javeriana; 2004. p.235-7.

6. Schaap T, Bach G. Incidence of mucopolysaccharidoses in Israel: is Hunter disease a "Jewish disease"? Hum Genet 1980;56:221-3.

7. Young ID, Harper PS. Incidence of Hunter's syndrome. Hum Genet 1982;60:391-2.

8. Lowry RB, Applegarth DA, Toone JR, Macdonald $E$, Thunem NY. An update on the frequency of mucopolysacharide syndromes in British Columbia. Hum Genet 1990;85:389-90.

9. Vellodi A, Young E, Cooper A, Lidchi V, Winchester B, Wraith J. Long-term follow-up following bone marrow transplantation for Hunter disease. J Inherit Metab Dis 1999;22:638-48

10. Kaye EM. Lysosomal storage diseases. Curr Treat Options Neurol 2001;3:249-56.
11. Brown FR 3rd, Hall CW, Neufeld EF, Muñoz LL, Braine $\mathrm{H}$, Andrzejewsky $\mathrm{S}$ et al. Administration of iduronate sulfatase by plasma exchange to patients with Hunter syndrome: a clinical study. Am J Med Genet 1982;13:309-18.

12. Templeton N, Lasic D. Gene therapy. Therapeutic mechanisms and strategies. First edition. New York: Marcel Dekker Inc.; 2000. p.584.

13. Rattazi C, Dobrenis K. Enzyme replacement: overview and prospects. En: Desnick R, editor. Treatment of genetic diseases. First edition. New York: Churchill Livingstone; 1991. p131-51.

14. Bond CS, Clements PR, Ashby SJ, Collyer CA, Harrop SJ, Hopwood JJ et al. Structure of human lysosomal sulfatase. Structure 1997;5:277-89.

15. Hockney RC. Recent developments in heterologous protein production in Escherichia coli. Trends Biotechnol 1994;12:456-63

16. Romanos MA, Scorer CA, Claret JJ. Foreign gene expression in yeast: a review. Yeast 1992;8:423-88.

17. Shapira E, Blitzer M, Miller J, Africk D. Biochemical genetics. A laboratory manual. First edition. New York: Oxford University Press; 1989. p.146.

18. Voznyi YV, Keulemans JL, van Diggelen OP. A fluorometric enzyme assay for the diagnosis of MPS II (Hunter Disease). J Inherit Metab Dis 2001;24:675-80.

19. Ausubel F, Brent R, Kingston R, Moore D, Seidman J, Smith $\mathrm{J}$ et al. Short protocols in molecular biology. Fourth Edition. Toronto, Canada: John Wiley and Sons Inc.; 1999. p.10-7

20. Espejo A, Sosa A, Carrascal A, Cifuentes C, Barreto A. Producción de la proteína humana recombinante Hsc70 y su aplicación en un sistema ELISA. Universitas Scientiarum 2004;9:69-80.

21. Landázuri $P$, Gunturiz ML, Gómez LA, Poutou R, Torres AL, Echeverri OY et al. Expresión trasiente de la iduronato 2 sulfato sulfatasa humana recombinante. Revista de la Asociación Colombiana de Ciencias Biológicas 2003;45:22-31.

22. Parkinson EJ, Muller V, Hopwood JJ, Brooks DA Iduronate-2-sulphatase protein detection in plasma from mucopolysaccharidosis type II patients. Mol Genet Metab 2004;81:58-64

23. Parkinson-Lawrence E, Turner C, Hopwood J, Brooks D. Analysis of normal and mutant iduronate-2sulphatase conformation. Biochem J 2005;386:395400 . 